\title{
The risk of urinary retention following robot-assisted radical prostatectomy and its impact on early continence outcomes
}

Mansour Alnazari, MD ${ }^{1,2}$; Marc Zanaty, $\mathrm{MD}^{1,2}$; Khaled Ajib, $\mathrm{MD}^{1,2}$; Assaad El-Hakim, MD, FRCSC $^{2}$; Kevin C. Zorn, MD, FRCSC ${ }^{1}$

${ }^{1}$ Section of Urology, Department of Surgery, Centre Hospitalier de l’Université de Montréal; ${ }^{2}$ Division of Robotic Urology, Department of Surgery, Hôpital du Sacré Cœur de Montréal; Montreal, QC, Canada

Cite as: Can Urol Assoc J 2017 Dec. 22; Epub ahead of print. http://dx.doi.org/10.5489/cuaj.4649

Published online December 22, 2017

$* * *$

\section{Abstract}

Introduction: We aimed to evaluate the risk factors of acute urinary retention (AUR) following robot-assisted radical prostatectomy (RARP), as well as the relationship of AUR with early continence outcomes.

Methods: The records of 740 consecutive patients who underwent RARP by two experienced surgeons at our institution were retrospectively reviewed from a prospectively collected database. Multiple factors, including age, body mass index (BMI), international prostate symptom score (IPSS), prostate volume, presence of median lobe, nerve preservation status, anastomosis time, and catheter removal time (Day 4 vs. 7), were evaluated as risk factors for AUR using univariate and multivariate analysis. The relation between AUR and early return of continence (one and three months) post-RARP was also evaluated.

Results: The incidence of clinically significant vesico-urethral anastomotic (VUA) leak and AUR following catheter removal were $0.9 \%$ and $2.2 \%$ (17/740), respectively. In men who developed AUR, there was no significant relationship with regards to age, BMI, IPSS, prostatic volume, median lobe, nerve preservation, or anastomosis time; however, the incidence of AUR was significantly higher for men with catheter removal at Day 4 (4.5\% [16/351]) vs. Day 7 (0.2\% [1/389]) $(p=0.004)$. Moreover, patients with early removal of the catheter (Day 4) who developed AUR had an earlier one-month return of 0-pad continence $87.5 \%(14 / 16)$ compared to patients without AUR 45.6\% (153/335), with no significant difference at three months.

Conclusions: While AUR is an uncommon complication of RARP, its incidence is much higher than VUA leakage. Further, it is often not well-discussed during patient counselling preoperatively. Moreover, earlier return of urinary continence was observed in patients experiencing AUR following RARP exclusively with catheter removal at Day 4. Future studies are warranted to validate the long-term impact of AUR on continence outcomes. 


\section{Introduction}

Robot assisted radical prostatectomy (RARP) has emerged as the dominant surgical procedure for men with localized prostate cancer. In 2010, nearly $80 \%$ of all prostatectomies in the USA were performed with robotic assistance. ${ }^{1}$ RARP has been found to be independently associated with less blood loss, shorter length of catheterization, and hospital stay when compared with traditional retropubic radical prostatectomy (RRP).,3

Although leaving a temporary indwelling catheter is standard practice after radical prostatectomy to allow anastomotic healing, urinary catheterization represents a source of infection, significant discomfort, and anxiety for the patient following radical prostatectomy. ${ }^{4}$ However, its placement for 7-14 days helps to avoid unwanted anastamotic urinary leakage and possible retention due to edema. The optimal time of catheter removal to avoid vesico-urethral anastomosis (VUA) leakage and prevent retention is unknown. However, several studies have demonstrated higher incidence of AUR with early removal of the catheter resulting in catheter replacement and longer catheterization time. ${ }^{5}$ Most experiences report Foley removal on days 5-7. Moreover, following radical prostatectomy, urinary incontinence is one of the most common and bothersome side effects following prostatectomy. ${ }^{6}$ The pathophysiology of urinary incontinence after RARP is multifactorial including bladder neck dysfunction, detrusor instability, decreased compliance, external sphincter damage, and injury to the pelvic diaphragm and its innervation. ${ }^{7}$ The impact of Foley duration and its impact on long term urinary continence have not been well studied.

As such, we sought to evaluate the risk factors of AUR following RARP including the timing of catheter removal, and to study the relationship of urinary retention on continence outcomes. To the best of our knowledge, this is the first study to evaluate a relation between AUR and early urinary control following RARP.

\section{Methods}

A total of 740 men from a prospectively collected database with clinically localized prostate cancer who underwent RARP between 2006 and 2014 at our institute were retrospectively reviewed. Institutional-review board approval was obtained for the study. All RARPs were performed by one of 2 robotic fellowship-trained surgeons as per our described surgical technique. ${ }^{8-10}$ Men with previous prostate surgery, previous pelvic radiotherapy or neo-adjuvant chemotherapy were excluded. Patient and perioperative data were evaluated, particularly the speculated risk factors for AUR, including: age, body mass index (BMI), international prostatic symptom score (IPSS), prostate volume, presence of median lobe, nerve preservation, VUA surgical time, and catheter removal date were collected and reviewed. Urinary catheter removal was performed without a cystogram at postoperative day 4 in 351 men (surgeon 1) while the remaining 389 men had the removal at day 7 postoperatively (surgeon 2). In event of AUR or anastomotic leakage, a14Fr or 16Fr Foley catheter was reinserted by a heath care provider or a medical nurse without cystoscopic guidance, and the patient was instructed to keep the catheter for 3-7 days to allow the VUA edema to resolve. 
Risk factors for urinary retention were evaluated by univariate and multivariate analysis using logistic regression models, taking retention as the response variable and predictors of retention mentioned above as response variables. In the group of patients who were found to have higher incidence of AUR (Day 4), continence at 1 and 3 months was compared between patients who had AUR versus patients who did not have AUR (exclusively inside this group). Continence was measured by the number of pads per 24 hours, considered as a categorical variable and divided to 4 categories: 0, 1 security, 1 pad, 2 or more pads. Continence was defined as 0 pads per 24 hours. Categories were compared using Chi-square test and Fisher exact test for categorical variables.

\section{Results}

Overall patient demographics and pathological features are summarized in table $\mathbf{1}$. Among the 740 included RARP men, only 16 patients (2.2\%) developed AUR after removal of the urinary catheter. All were managed with re-catheterization for an additional 3-7 days to allow for VUA edema resolution. No patient developed a second episode of retention. Moreover, 7 men (0.9\%) developed anastomotic leakage several days after removal of the catheter and the diagnosis was confirmed by cystogram. All such men were successfully managed with re-insertion of a urinary catheter, antibiotics and other conservative measures. Long-term assessment revealed that 3 patients (0.4\%) developed bladder neck contracture (2 patients at 6 months and 1 patient at 4 months following RARP) and managed with a single endoscopic bladder neck incision. No patient with VUA urinary leakage or bladder neck contracture had AUR following the surgery. As previously noted, the urinary catheter was removed in 351 and 389 men at day 4 and 7 respectively. Immediate AUR was observed in $4.5 \%$ (16 patients) and 0.2\% (1 patient) in each group. This observation was also a statistically significant risk factor for he development of AUR in both univariate $(\mathrm{p}=0.004)$ and multivariate analysis $(\mathrm{p}=0.003)$. Other variables including patientrelated factors (age, BMI, prostate transrectal volume, preoperative IPSS, and presence of a median lobe) and surgery-related factors (specifically VUA anastomosis time, intraoperative anastomotic leakage, and nerve preservation) were also analyzed as risk factors for the development of AUR post RARP with no statistically significant difference $(\mathrm{P}<0.05$ for all) (Table 2,3).

With regards to short-term urinary continence outcomes following RARP, men who experienced AUR had a favorable outcome during the first month (table 4). More specifically, 0pad continence rate was significantly higher ( $p$ value: 0.0142 ) at 1 month in patients with AUR (88\% vs 47\%; $\mathrm{p}=0.01$ ). However, no significant continence differences were observed at 3months (all $\mathrm{p}>0.05)$.

\section{Discussion}

The evolution of minimally invasive techniques for the treatment of prostate cancer has seen a substantial evolution over the recent decade with the introduction of robotic assistance. Reduced morbidity including a decrease in hospitalization, convalescence time, catheterization time, bladder

neck contracture, leakage rate, blood loss and transfusion rate are likely factors at play. ${ }^{11-14}$ VUA 
related outcomes are noted to be improved with RARP, including urinary continence, VUA leak and bladder neck contracture. ${ }^{15,16}$

In previous RRP series, catheter replacement was most often related to VUA urinary leakage and urinoma. In the current series, consistent with other large, high-volume RARP series, AUR (2.2\%) was a more common adverse event when compared to VUA leakage (0.9\%). Improvements in tissue reconstruction with robotics including less tissue handling, avoidance of mucosa eversion, continuous suture technique combined with posterior reconstruction are contributing factors to improved VUA.

AUR is uncommon but poorly understood complication of RARP. Patel et al reported that postoperative anastomotic edema, postoperative pain, and increased bladder neck smooth muscle tone as possible etiologies of AUR following laparoscopic radical prostatectomy. ${ }^{4}$ AUR also might be a predictor of subsequent future urethral stricture and bladder neck contracture (BNC), as some investigators observed significant incidence (3.6\%) of urethral stricture in 44 patients whom developed AUR in a 1,289 series of patients following radical prostatectomy. ${ }^{17}$ This was not observed in our series. In addition, the management of AUR requires reinsertion of an indwelling catheter, which impacts patient quality of life, increases the rate infection and bladder irritative symptoms. ${ }^{12}$ Better understanding of AUR risk factors and prevention with longer Foley placement could avoid the risks of replacing a catheter and the psychological burden on patients. ${ }^{5}$

Upon a review of the published literature, the incidence of AUR following radical prostatectomy (RRP, LRP, and RARP) varies considerably between 2-21\%. Table 5 summarizes large volume series for all 3 surgical approaches. In our current retrospective review of 740 patients, AUR occurred in $2.2 \%$ of the patients, which is comparable to large series of RARP. Even with the meta-analysis by Ficarra et al, the incidence of AUR is $<1 \%$ in large RARP published series. ${ }^{18}$ Moreover, there was no patient or surgery-related factor identified to be a significant predictor for the development of AUR except for the duration of catheterization. The optimal catheterization time after radical prostatectomy is unknown and its relation to the development of AUR is debated.

Traditionally, urinary catheter removal after RRP has been performed between 10 and 21 days postoperatively without strong, supportive evidence. ${ }^{19-21}$ Lepor et al reported that removal of the catheter on post-operative day 7 is both feasible and desirable after excluding extravasation by a cystogram following RRP. ${ }^{22}$ Patel et al reported significant higher incidence of AUR (19\%) when the catheter was removed at day 3 or 4 compared to $3 \%$ at day 7 following RRP. ${ }^{4}$ Another recent study done on 1026 patients who underwent RARP concluded that although early removal of the catheter (day 4 or 3 ) had no increase in the rate of anastomotic leak it carries higher risk of AUR compared to catheter removal at 5 days or more. ${ }^{5}$ In another series of 114 patients who underwent LRP the catheter was safely removed as early as post-operative day 2 in carefully selected patients on the basis of the integrity of the vesico-urethral anastomosis and the ease of intraoperative re-catheterization. However, $17 \%$ of the patients developed AUR. ${ }^{23}$ Interestingly, Tiguret et al found no significant difference in the incidence of AUR if the catheter was removed 
at day 4 (3\%) or later (3\%) following RRP, but noticed better continence rate and less anastomotic stricture rate with earlier removal of the catheter. ${ }^{24}$

With regards to RARP, a dedicated study performed on 74 men following RARP observed that the rate of AUR developed in $11 \%$ of patients had their catheter removed 2 days after the surgery vs $8 \%$ when the catheter was left till day 6 with no significant statistical difference. ${ }^{25}$ This reflects on the time related resolution of the VUA edema, particularly with the Van Velthoven continuous suture closure. Additionally, other investigators consider early removal of the catheter as a predictive factor for development of AUR.

In the current study, the timing of removal of the urinary catheter was the only significant factor for development of AUR on both univariate and multivariate analysis. The rate of AUR in patients whose catheters were removed at day 4 and those whose catheters were removed at day 7 was $4.5 \%$ and $0.2 \%$, respectively. Our anastomotic leak rate was $0.9 \%$ while most of the patients with leak (71\%(5/7)) had their catheter removed at day 4. In case of development of AUR some investigators advised to reinsert the urinary catheter under cystoscopic guidance because of the potential risk of disruption of the vesicourethral anastomosis (VUA) and bladder neck reconstruction. ${ }^{4}$ We believe that the utilization of robotic technology in prostatectomy has led to a better visualization and integrity of the VUA as all patients whom developed AUR in our series where treated with recatheterization on the word or emergency department with no difficulty and without the need of any adjuncts. None of the cases needed a urological input, and no one of the patients with AUR developed leak or another episode of AUR.

With regards to impact on urinary control and long-term continence, there are few studies, which have addressed this relationship. Gratzke et al reported no significant difference with regard to early continence rate if the catheter was removed on day 2 or 6 following RARP using international consultation on incontinence Questionnaire-Male lower urinary tract symptoms long form (ICIQ MLUTS LF). On the other hand, some investigators observed higher continence rate at 3, 9, and 12 month following RRP in favor of patients with earlier removal of catheter at day 4 compared to later than day 4 by using the number of pads/ $24 \mathrm{~h}$ as an indicator for continence level. ${ }^{24,25}$ Another study included 113 men who underwent LRP and divided them into 2 groups based on the timing of catheter removal (day 2 vs 4 ) following the surgery. There was no significant difference in the incidence of AUR between the two groups, but continence rate was significantly lower with earlier removal of catheter. Urinary incontinence was measured using the urine loss ratio (ULR) and showed that patients with AUR with catheter removal at day 2 showed lower continence when compared to patients with catheter removal at day 4. Multivariate analysis identified AUR after catheter removal on day 2 as the only predictive factor for incontinence at 6 and 9 months after LRP (OD 4.472, P = 0.03). ${ }^{26}$ Meanwhile, in our series, AUR was found to have a positive effect on continence rate at 1 month with no significant impact at 3 months. Despite its merits, our study has number of limitations worthy of mention. These include the single institution, retrospective nature of the study. Moreover, the measurement of continence rate was dependent on patients' reports with lacking of objective tests. However all data was obtained prospectively into an IRB-approved database. Despite these limitations we believe that our results 
indicate that leaving the urinary catheter 7 days following RARP is safer in the reduction of AUR incidence following RARP.

\section{Conclusion}

AUR is an uncommon complication of RARP and is often not well highlighted during patient counseling. However, it appears that its incidence is much higher than VUA urinary

leakage/extravasation. Early removal of the urinary catheter following the surgery at day 4 carries a higher risk of AUR when compared to day 7. Moreover, development of AUR has a positive effect on early continence rate only in patients with early catheter removal at day 4 post RARP. Further studies with longer follow up are required to evaluate the effect on the long-term outcomes of continence. 


\section{References}

1. Patel V. R., Sivaraman A. Current status of robot-assisted radical prostatectomy: progress is inevitable. Oncology. 2012;26:616-619.

2. Eifler JB, Cookson MS. Best evidence regarding the superiority or inferiority of robotassisted radical prostatectomy. Urol Clin North Am 2014;41:493-502.

3. Novara G, Ficarra V, Rosen RC, et al. Systematic review and metaanalysis of perioperative outcomes and complications after robot assisted radical prostatectomy. Eur Urol 2012;62:431-52.

4. Patel R., Lepor H. Removal of urinary catheter on postoperative day 3or 4 after radical retropubic prostatectomy. Urology 2003;61:156-160.

5. Khemees T. A., Novak R., Abazat R. Risk and prevention of acute urinary retension after robotic prostatectomy. Juro 2013;189:1432-1436.

6. Miller DC, Sanda MG, Dunn RL, et al. Long-term outcomes among localized prostate cancer survivors: Health-related quality-of-life changes after radical prostatectomy, external radiation, and brachytherapy. J Clin Oncol. 2005;23:2772-80.

7. Egawa S, Minei S, Iwamura M, et al. Urinary continence following radical prostatectomy. Jpn J Clin Oncol 1997;27:71-5. Epub 1997/04/01.

8. Zorn KC, Widmer H, Lattouf JB, et al. Novel method of knotless vesicourethral anastomosis during robot-assisted radical prostatectomy: Feasibility study and early outcomes in 30 patients using the interlocked barbed unidirectional V-LOC180 suture. Can Urol Assoc J. 2011;5:188-94. http://dx.doi.org/10.5489/cuaj.10194. [PMC free article] [PubMed]

9. Valdivieso RF, Hueber PA, Zorn KC, et al. Robot assisted radical prostatectomy: How I do it. Part II: Surgical technique. Can J Urol. 2013;20:7073-8. [PubMed]

10. Valdivieso RF, Hueber PA, Zorn KC. Robot assisted radical prostatectomy: how I do it. Part I: Patient preparation and positioning. Can J Urol. 2013;20:6957-61. [PubMed]

11. S. B. Bhayani, C. P. Pavlovich, T. S. Hsu, W. Sullivan, and L. M. Su, "Prospective comparison of short-term convalescence: laparoscopic radical prostatectomy versus open radical retropubic prostatectomy,” Urology, 2003;61;612-616.

12. A. Nadu, L. Salomon, A. Hoznek et al., "Early removal of the catheter after laparoscopic radical prostatectomy,” Journal of Urology,2001;166:1662-1664.

13. Lowrance WT, Parekh DJ. The rapid uptake of robotic prostatectomy and its collateral effects. Cancer. 2012;118:4-7. http://dx.doi.org/10.1002/cncr.26275. [PubMed]

14. Leow, J.J., Chang, S.L., Meyer, C.P. et al, Robot-assisted versus open radical prostatectomy: a contemporary analysis of an all-payer discharge database. Eur Urol. 2016; DOI: http://dx.doi.org/10.1016/j.eururo.2016.01.044 
15. Msezane LP, Reynolds WS, Gofrit ON, Shalhav AL, Zagaja GP, Zorn KC. Bladder neck contracture after robot-assisted laparoscopic radical prostatectomy: evaluation of incidence and risk factors and impact on urinary function. J Endourol. 2008 Jan;22(1):97-104.

16. Walz J, Epstein JI, Ganzer R, Graefen M, Guazzoni G, Kaouk J, Menon M, Mottrie A, Myers RP, Patel V, Tewari A, Villers A, Artibani W. Eur. A Critical Analysis of the Current Knowledge of Surgical Anatomy of the Prostate Related to Optimization of Cancer Control and Preservation of Continence and Erection in Candidates for Radical Prostatectomy: An Update. Eur Urol. 2016 Aug;70(2):301-11.

17. Montgomery JS, Gayed BA, Daignault S et al: Early urinary retention after catheter removal following radical prostatectomy predicts for future symptomatic urethral stricture formation. Urology. 2007 Aug;70(2):324-7.

18. Ficarra, Vincenzo, Stefano Cavalleri, Giacomo Novara, Maurizio Aragona, and Walter Artibani. "Evidence from Robot-Assisted Laparoscopic Radical Prostatectomy: A Systematic Review." European Urology 51.1 (2007): 45-56.

19. Shelfo SW, Obek C, Soloway MS. Update on bladder neck preservation during radical retropubic prostatectomy: impact on pathologic outcome, anastomotic strictures, and continence. Urology. 1998;51(1):73-8.

20. Murphy GP, Mettlin C, Menck H, Winchester DP, Davidson AM. National patterns of prostate cancer treatment by radical prostatectomy: results of a survey by the American College of Surgeons Commission on Cancer. J Urol. 1994;152(5 Pt 2):1817-9.

21. Steiner MS, Morton RA, Walsh PC. Impact of anatomical radical prostatectomy on urinary continence. J Urol. 1991;145(3):512-4.

22. Lepor H, Nieder AM, Fraiman MC. Early removal of urinary catheter after radical retropubic prostatectomy is both feasible and desirable. Urology. 2001;58(3):425-9.

23. James $P$, Glackin A, Doherty A, Safe removal of the urethral catheter 2 days following laparoscopic radical prostatectomy. ISRN Oncology 2012; ID 912642,3

24. Tiguert R, Rigaud J, Fradet Y. Safety and outcome of early catheter removal after radical retropubic prostatectomy. Urology. 2004;63(3):513-7.

25. Gratzke C, Dovey Z, Novara G, Geurts N, Groote R, Schatteman P, Naeyer G, Gandaglia, Mottrie A, Early catheter, removal after robot-assisted radical prostatectomy: surgical technique and outcomes for the Aalst technique (ECaRemA study). J.eururo 2015.09.052.

26. Matsushima M, Miyajima A, Hattori S, Takeda T, Mizuno R, Kikuchi E, Oya M. Comparison of continence outcoms of early catheter removal op postoperative day 2 and 4 after laparoscopic radical prostatectomy: a randomized controlled trial. BMC Urology (2015) $15: 77$ 
Figures and Tables

\begin{tabular}{|c|c|c|}
\hline Variables & Mean & CI \\
\hline PSA & 6.66 & $6.32 ; 7.01$ \\
\hline Age (year) & 60.44 & 59.97; 60.90 \\
\hline BMI & 27.55 & $27.23 ; 27.88$ \\
\hline Prostate volume (g) & 50.22 & $48.95 ; 51.50$ \\
\hline $\begin{array}{r}\text { c stage } \%(n) \\
\text { cT1a } \\
\text { cT1b } \\
\text { cT1c } \\
\text { cT2a } \\
\text { cT2b } \\
\text { cT2c } \\
\text { cT3a }\end{array}$ & $\begin{array}{c}0.13(1) \\
0.13(1) \\
71.79(532) \\
19.83(147) \\
5.93(44) \\
1.34(10) \\
0.8(6)\end{array}$ & \\
\hline $\begin{array}{l}\text { Gleason biopsy \% (n) } \\
6 \\
7 \\
8 \\
9 \\
10 \\
\end{array}$ & $\begin{array}{c}34.10(252) \\
56.29(416) \\
73.07(540 \\
23(17) \\
0(0) \\
\end{array}$ & \\
\hline IPSS & 7.60 & 7.12; 8.07 \\
\hline EBL & 263.39 & $252.13 ; 274.65$ \\
\hline OR time & 183.26 & 179.35; 187.18 \\
\hline
\end{tabular}

BMI: body mass index; CI: confidence interval; EBL: estimated blood loss; IPSS: International Prostate Symptom Score; OR: operating room; PSA: prostate-specific antigen. 


\begin{tabular}{|l|c|c|c|}
\hline \multicolumn{5}{|l|}{ Table 2. Univariate analysis of potential predictors of AUR } \\
\hline Variables & OR & CI & p \\
\hline Catheter removal day & 0.053 & $0.003 ; 0.264$ & $\mathbf{0 . 0 0 4}$ \\
\hline Age (year) & 0.933 & $0.867 ; 1.004$ & $\mathbf{0 . 0 6}$ \\
\hline BMI & 0.988 & $0.872 ; 1.097$ & $\mathbf{0 . 8 3 9}$ \\
\hline Prostate volume (g) & & & $\mathbf{0 . 4 0 9}$ \\
\hline Anastomosis time & 0.986 & $0.951 ; 1.015$ & $\mathbf{0 . 9 6 3}$ \\
\hline IPSS & 1.001 & $0.946 ; 1.043$ & $\mathbf{0 . 4 0 5}$ \\
\hline Median lobe & 0.965 & $0.877 ; 1.041$ & $\mathbf{0 . 7 6 7}$ \\
\hline & 1.210 & $0.276 ; 3.784$ & $\mathbf{0 . 9 2 2}$ \\
\hline
\end{tabular}

AUR: acute urinary retention; BMI: body mass index; CI: confidence interval; IPSS: International Prostate Symptom Score; OR: odds ratio.

\begin{tabular}{|l|c|c|c|}
\hline \multicolumn{2}{|l}{ Table 3. Multivariate analysis of potential predictors of AUR } \\
\hline Variables & OR & CI & p \\
\hline Catheter removal day & 0.940 & $0.911 ; 0.971$ & $<0.001$ \\
\hline Age (year) & 0.998 & $0.996 ; 1.001$ & 0.209 \\
\hline & & & 0.904 \\
BMI & 1.000 & $0.996 ; 1.003$ & 0.520 \\
\hline IPSS & & & 0.723 \\
\hline Prostate volume (g) & 0.999 & $0.997 ; 1.002$ & 0.103 \\
\hline Anastomosis time & 1.000 & $0.999 ; 1.001$ & 0.976 \\
\hline Nerve preservation & 1.001 & $1.000 ; 1.003$ & 0.587 \\
\hline Median lobe & 1.000 & $0.980 ; 1.021$ & \\
\hline
\end{tabular}

AUR: acute urinary retention; BMI: body mass index; CI: confidence interval; IPSS: International Prostate Symptom Score; OR: odds ratio. 


\begin{tabular}{|c|c|c|c|c|c|}
\hline No of patients & 0 pad & 1 security pad & 1 pad & $\begin{array}{c}2 \text { or more } \\
\text { pads }\end{array}$ & $\mathbf{p}$ \\
\hline $\begin{array}{l}1 \text { month } \\
\text { AUR } \\
\text { No AUR }\end{array}$ & $\begin{array}{c}14(88 \%) \\
153(47 \%) \\
\end{array}$ & $\begin{array}{c}1(6 \%) \\
68(21 \%) \\
\end{array}$ & $\begin{array}{c}1(6 \%) \\
44(13 \%)\end{array}$ & $\begin{array}{c}0 \\
64(19 \%) \\
\end{array}$ & 0.0142 \\
\hline $\begin{array}{c}3 \text { months } \\
\text { AUR } \\
\text { No AUR }\end{array}$ & $\begin{array}{c}15(94 \%) \\
227(70 \%)\end{array}$ & $\begin{array}{c}0 \\
50(15 \%)\end{array}$ & $\begin{array}{c}1(6 \%) \\
27(8 \%)\end{array}$ & $\begin{array}{c}0 \\
25(7 \%)\end{array}$ & 0.201 \\
\hline
\end{tabular}

AUR: acute urinary retention; RARP: robot-assisted radical prostatectomy.

\begin{tabular}{|c|c|c|c|c|c|c|c|}
\hline Author & Year & $\begin{array}{c}\text { No of } \\
\text { patients }\end{array}$ & $\begin{array}{l}\text { Type of } \\
\text { surgery }\end{array}$ & $\begin{array}{l}\text { BNC } \\
\text { rate }\end{array}$ & $\begin{array}{c}\text { Leakage } \\
\text { rate }\end{array}$ & $\begin{array}{l}\text { Overall } \\
\text { incidence } \\
\text { of AUR }\end{array}$ & $\begin{array}{c}\text { Incidence of } \\
\text { AUR } \\
\text { in relation to } \\
\text { catheterization } \\
\text { time }\end{array}$ \\
\hline Lepor et al ${ }^{17}$ & 2001 & $\begin{array}{c}135 \\
\text { (excluding } \\
44 \text { ptn } \\
\text { with leak) }\end{array}$ & RRP & $5 \%$ & $24 \%$ & $12 \%$ & $\begin{array}{l}\text { 15\% POD } 7 \\
0 \% \text { POD } 14\end{array}$ \\
\hline Patel et $\mathrm{al}^{4}$ & 2003 & 151 & RRP & $14 \%$ & $23 \%$ & $15 \%$ & $\begin{array}{c}\text { 19\% POD } 3 \text { or } \\
4 \\
3 \% \text { POD } 7 \text { or } \\
\text { more }\end{array}$ \\
\hline $\begin{array}{l}\text { Noghuchi et } \\
\text { al }\end{array}$ & 2004 & 70 & RRP & $2 \%$ & $4 \%$ & $21 \%$ & $21 \%$ POD 3 \\
\hline $\begin{array}{l}\text { Tiguert et } \\
\mathrm{al}^{20}\end{array}$ & 2003 & 342 & RRP & $4 \%$ & $19 \%$ & $3 \%$ & $\begin{array}{c}\text { 3\% POD } 4 \\
3 \% \text { POD } 5 \text { or } \\
\text { more }\end{array}$ \\
\hline Souto et al & 2004 & 73 & RRP & $2 \%$ & N/A & $3 \%$ & $\begin{array}{c}5 \% \text { POD } 7 \\
0 \% \text { POD } 14\end{array}$ \\
\hline James et $l^{18}$ & 2012 & 64 & LRP & $\mathrm{N} / \mathrm{A}$ & $\mathrm{N} / \mathrm{A}$ & $17 \%$ & 17\% POD 2 \\
\hline Matsushima & 2015 & 113 & LRP & $0 \%$ & N/A & $18.6 \%$ & 22\% POD 2 \\
\hline
\end{tabular}




\begin{tabular}{|l|c|c|c|c|c|c|c|}
\hline et $^{21}$ & & & & & & & $14 \%$ POD 4 \\
\hline $\begin{array}{l}\text { Khamees et } \\
\mathrm{al}^{5}\end{array}$ & 2013 & 1,026 & RARP & $0.2 \%$ & $0.9 \%$ & $2 \%$ & $\begin{array}{c}\text { 6\% POD 4 or 3 } \\
0.5 \% \text { POD 5 or } \\
\text { more }\end{array}$ \\
\hline $\begin{array}{l}\text { Gratzke et } \\
\mathrm{al}^{19}\end{array}$ & 2015 & 74 & RARP & $1.5 \%$ & $2 \%$ & $9 \%$ & $\begin{array}{c}11 \% \text { POD } 2 \\
8 \% \text { POD } 6\end{array}$ \\
\hline
\end{tabular}

AUR: Acute urinary retention; LRP: laparoscopic radical prostatectomy; POD: post-operative day; RARP: robot-assisted radical prostatectomy; RRP: retropubic radical prostatectomy. 